\title{
OPEN Leveraging internet search data to assess prevalence, interest, and unmet needs of sarcoidosis in Germany
}

\author{
Charlotte Hilker ${ }^{1}$, Linda Tizek ${ }^{1,2}$, Melvin Rüth ${ }^{1}$, Maximilian Schielein ${ }^{2,3}$, Tilo Biedermann ${ }^{1}$ \& \\ Alexander Zink ${ }^{1,3,4 凶}$
}

Sarcoidosis is a multisystemic disease of connective tissue with granuloma formation of unknown etiology and unclear prevalence. Internet search data has been shown to correlate with disease incidences and the population's interest as well as seasonal variations. Accordingly, aim of this study was to leverage internet search data on sarcoidosis-related keywords to identify unmet needs, geographical and seasonal factors influencing sarcoidosis and estimating its prevalence. In this retrospective longitudinal study, Google Ads Keyword Planner was used to determine the internet search volume of terms related to sarcoidosis across Germany as a whole and in 17 major German cities between July 2015 and June 2019. Identified keywords were qualitatively categorized, converted into number of searches per 100,000 inhabitants and analyzed including regional and seasonal differences. With 3,068,200 queries and 425 different sarcoidosis-related search terms in the studied time period, the search volume was very high for a rare disease. Most searches (67.9\%) related to general disease information with "sarcoidosis", "Löfgren's syndrome", "sarcoidosis lung", "Morbus Boeck" and "neurosarcoidosis" as the top five keywords. Searches per 100,000 inhabitants were comparable in all 17 cities but higher than in Germany as a whole. Overall, the search volume increased from 2015 to 2019 and peaked annually in European springtime with annual lows in European autumn and winter months. The overall high search volume suggests an unmet need for sarcoidosis-related information and a diagnostic gap. Seasonal fluctuations indicate environmental as well as climatic factors that may influence sarcoidosis.

Sarcoidosis, also known as Boeck's disease, is a multisystemic disease of connective tissue with granuloma formation and is described as the chameleon among the multisystemic diseases because of its varying manifestations, initial clinical signs, and course from patient to patient ${ }^{1,2}$. Histologically, non-necrotic granulomas with giant multinucleated cells dominate ${ }^{1}$. With an average lung involvement of about $90 \%$, sarcoidosis most frequently causes pulmonary manifestations and often affects the mediastinal and hilar lymph nodes ${ }^{3,4}$. The prognosis depends on the type of sarcoidosis, the response to therapy, and the general condition of the individual ${ }^{5}$. Prevalence and incidence are not known for certain partly due to the disease's nonspecific symptoms and its subsequent long diagnostic process ${ }^{6,7}$. In Europe, the annual sarcoidosis incidence is estimated at 5-60 cases per 100,000 inhabitants with a lifetime prevalence of 44 cases per 100,000 inhabitants ${ }^{8,9}$. Overall, it is estimated that there are about 30,000 cases in Germany with its total population of 83 million. The etiology of sarcoidosis is still unclear ${ }^{5}$. Currently, it is assumed that in a genetically predisposed person an immune dysfunction can be triggered by an as yet unidentified environmental factor ${ }^{4}$. This immune disorder, in turn, triggers a cascade which ends in a systemic granulomatous inflammation ${ }^{5}$. Infectious agents are repeatedly discussed as being possible environmental triggers, although a case-control study based on Swedish population registers found no significant correlation between infectious diseases and the development of sarcoidosis ${ }^{10}$. However, other studies

\footnotetext{
${ }^{1}$ Department of Dermatology and Allergy, Technical University of Munich, School of Medicine, Biedersteiner str. 29, 80802 Munich, Germany. ${ }^{2}$ Institute for Medical Information Processing, Biometry, and Epidemiology, Ludwig-Maximilians-University Munich, Munich, Germany. ${ }^{3}$ Unit of Dermatology and Venerology, Department of Medicine, Karolinska Institutet, Karolinska University Hospital, Stockholm, Sweden. ${ }^{4}$ Division of Dermatology and Venereology,Department of Medicine Solna, Karolinska Institutet, K2 Medicin, Solna, K2, 17177 Stockholm, Sweden. ${ }^{\square}$ email: alexander.zink@ki.se
} 
concluded that exposure to aerosol infectious as well as seasonal and geographical variations in disease incidence could provide indications of the etiological significance of infectious agents ${ }^{11-14}$. Studies have also shown that the number of sarcoidosis cases varies within a country depending on the region. Although no clear urban or rural differentiation can be identified ${ }^{15,16}$.

There are no clear epidemiological data on prevalence and incidence of sarcoidosis in Germany. One approach to better understand the incidence and prevalence of diseases is to analyse the search volume of related search terms in online search engines such as Google, as the Internet is used as a common source of health information ${ }^{17,18}$. Approximately $95 \%$ of Germans use Google as a search engine in everyday life, which is why data tracking offers a variety of possibilities ${ }^{19}$. As demonstrated in previous studies, the analysis of Google search data is an unconventional approach to investigating people's needs and interest in various diseases ${ }^{20,21}$. Furthermore, websearch data has been shown to significantly correlate with the incidence of infectious diseases ${ }^{22}$. Hence, the aim of this study was to analyse nationwide and regional internet search data on sarcoidosis in Germany to identify unmet needs and geographical factors influencing the disease.

\section{Methods}

Study design. In this retrospective longitudinal analysis, Google Ads Keyword Planner was used to assess the search volume of terms related to the German word for sarcoidosis ('Sarkoidose') across Germany as a whole and in 17 large German cities (Berlin, Bremen, Cologne, Dresden, Erfurt, Frankfurt, Freiburg, Hamburg, Hannover, Kaiserslautern, Kiel, Munich, Muenster, Nuremberg, Rostock, Saarbrucken, and Stuttgart) between July 2015 and June 2019. Cities were chosen not only for their size but also for their geographic distribution across the country. In order to provide a better overview, the selected cities were allocated according to their geographical location as north, east, south and west and then graphically displayed together accordingly. The Keyword Planner is normally used in advertising to optimize marketing campaigns, but since the tool provides the monthly search volume of a specific topic, it can also be used for scientific purposes ${ }^{23}$. The term search volume applies to the number of searches for a topic or search term. To assess its volume within a specific field, words are initially entered into the Keyword Planner; thereupon, the program provides keywords that are most relevant to the topic. Only data from German IP addresses using Google in the German language were considered. Due to the described seasonal differences in sarcoidosis incidence, we defined the summer/spring months as March to August and the autumn/winter months as September to February ${ }^{13}$.

Statistical analysis. All identified keywords were qualitatively assessed and classified by the authors. Keywords that were not relevant to sarcoidosis were excluded from analysis (e.g. "tuberculosis" "rheumatism"; Fig. 1), whereas search terms that did not directly contain the term sarcoidosis (e.g. "erythema nodosum" or "lung node") but were medically associated with sarcoidosis were considered. All remaining keywords were further divided into five categories: "symptoms" (e.g. "sarcoidosis symptoms"), "diagnostics" (e.g. "ace laboratory value"), "form of sarcoidosis/organ infestation" (e.g. "sarcoidosis muscle", "sarcoidosis nerves", and "sarcoidosis lung"), and "therapy" (e.g. "alternative method sarcoidosis"). Search terms that did not fit into any of these categories were assigned to a "general" category (e.g. "sarcoidosis", "Boeck's disease", and "what is sarcoidosis?"). Each search term was assigned to only one category. To compare differences in search behavior across Germany, the search volume of each city was divided by the respective number of inhabitants and then expressed per 100,000 inhabitants. Geodata for administrative boundaries from the German Federal Agency for Cartography and Geodesy were collected using the geographic information system QGIS, version 2.14.22 (QGIS Development Team $)^{24}$.

\section{Results}

Overall, 433 keywords associated with sarcoidosis were identified using the Keyword Planner. Of those, eight keywords were excluded from the final analysis as they were not relevant. The remaining 424 keywords had an overall search volume of 3,068,200 queries across Germany from July 2015 to June 2019 (Fig. 1). The category "general" had the highest number of search queries with 2516 queries per 100,000 inhabitants (67.9\%). Within this category, the terms "sarcoidosis", "Boeck's disease", "systemic disease", "sarcoidosis nutrition" and "sarcoidosis lung life expectancy" (in descending order), represented the most searched terms. The second most searched category was "form of sarcoidosis/organ manifestation" with 778 queries per 100,000 inhabitants (21.0\%). When considering the localization of sarcoidosis, people searched for almost all organ systems. With $19.8 \%$ of all keywords, people searched most frequently for the lung with keywords like "ace lung", "autoimmune disease lung", and "granulomatous lung disease". The five most commonly searched keywords were "sarcoidosis" (2,041 searches/100,000 inhabitants), "Löfgren's syndrome" (120 searches/100,000 inhabitants), "sarcoidosis lung" (99 searches/100,000 inhabitants), "Morbus Boeck" (91 searches/100,000 inhabitants), and "neurosarcoidosis" (69 searches/100,000 inhabitants, Tables 1 and 2).

Comparisons between cities. Differences in search frequency were identified between cities, but no considerable differences in search frequency were observed within the geographical regions. In all 17 cities examined, the number of search queries per 100,000 inhabitants was higher than the national average ( 3706 searches/100,000 inhabitants). The cities with the lowest relative search volume were Berlin (6909 searches/100,000 inhabitants), Bremen (8644 searches/100,000 inhabitants), and Hamburg (9677 searches/100,000 inhabitants). In contrast, the highest number of searches per 100,000 inhabitants was observed in Freiburg (20,293 searches/100,000 inhabitants), followed by Muenster (18,392 searches/100,000 inhabitants) and Kiel (17,157 searches/100,000 inhabitants, Fig. 2). Berlin, with a population of about 3.6 million inhabitants $(3,613,495)$, had a lower search volume per 100,000 inhabitants than Kaiserslautern, with a population of just under $100,000(99,864)$. The same can 


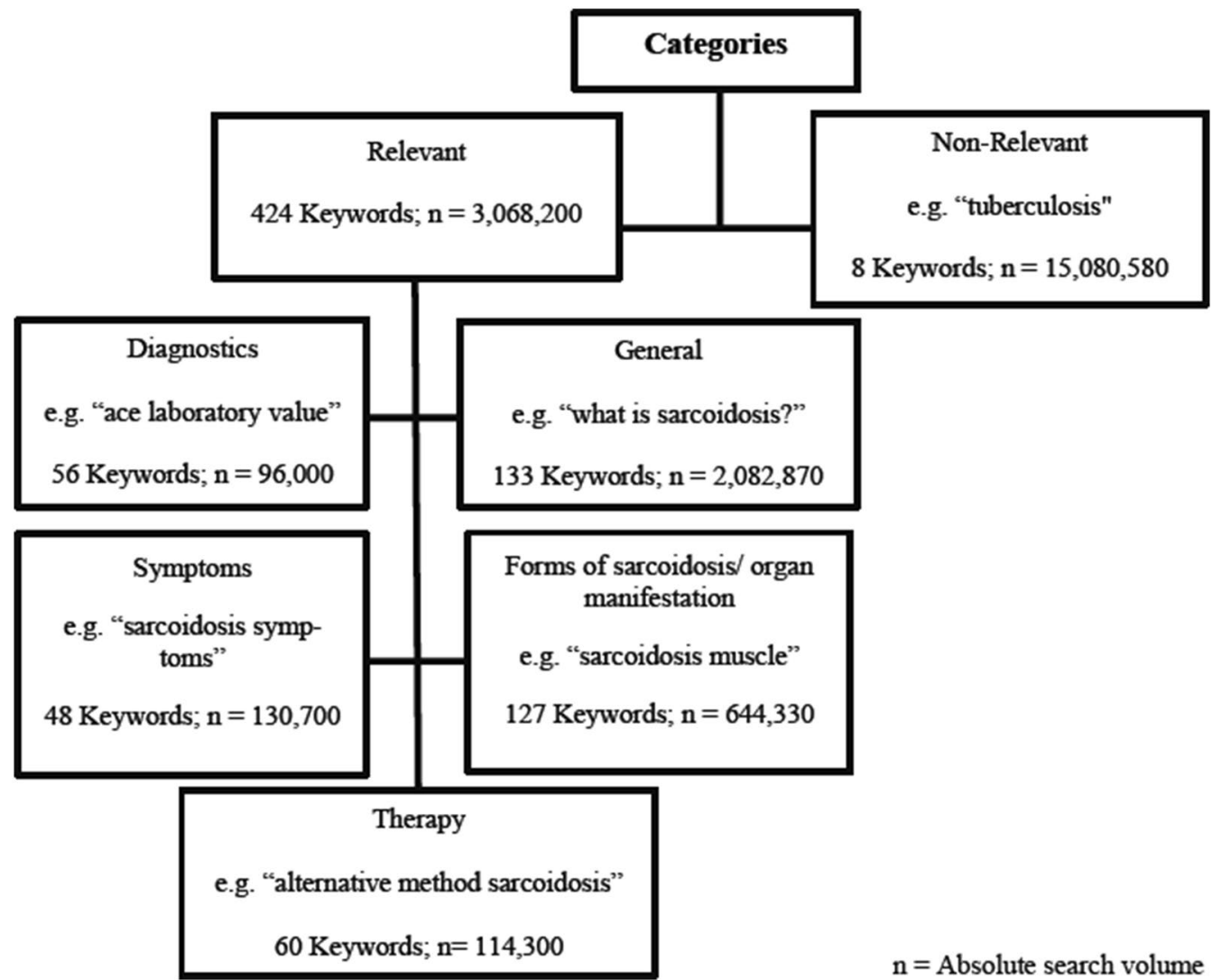

Figure 1. Categorization of the content of search terms identified by the Google Ads Keyword Planner.

\begin{tabular}{|l|l|l|l|}
\hline Keyword & Category & $\begin{array}{l}\text { Search volume per 100,000 } \\
\text { inhabitants }\end{array}$ & $\begin{array}{l}\text { Percentage of the total search } \\
\text { volume }\end{array}$ \\
\hline Sarcoidosis & General & 2040.5 & 55.1 \\
\hline Löfgren's syndrome & $\begin{array}{l}\text { Form of sarcoidosis/organ mani- } \\
\text { festation }\end{array}$ & 120.0 & 3.2 \\
\hline Sarcoidosis lung & $\begin{array}{l}\text { Form of sarcoidosis/organ mani- } \\
\text { festation }\end{array}$ & 98.9 & 2.7 \\
\hline Morbus Boeck & General & 90.6 & 2.4 \\
\hline Neurosarcoidosis & $\begin{array}{l}\text { Form of sarcoidosis/organ mani- } \\
\text { festation }\end{array}$ & 68.5 & 1.8 \\
\hline Sarcoidosis skin & $\begin{array}{l}\text { Form of sarcoidosis/organ mani- } \\
\text { festation }\end{array}$ & 50.3 & 1.4 \\
\hline Sarcoidosis symptoms & Symptoms & 43.0 & 1.2 \\
\hline Pulmonary sarcoidosis & $\begin{array}{l}\text { Form of sarcoidosis/organ mani- } \\
\text { festation }\end{array}$ & 31.4 & 0.8 \\
\hline
\end{tabular}

Table 1. The most frequently searched keywords related to sarcoidosis in Germany. The figure contains percentages related to 100,000 inhabitants and the percentage share of the search term in the total search volume.

be observed in Hamburg ( $\mathrm{n}=9477$, inhabitants $=1,830,584)$ and Freiburg $(\mathrm{n}=20,293$, inhabitants $=229,636)$, as well as in Munich, Kiel and Rostock (Fig. 2). Looking at the categorical distribution (Table 3), a larger proportion of search queries in the cities fell into the categories of sarcoidosis forms/organ manifestation, diagnostics, symptoms, and therapy than into the general category. In Freiburg, for example, $11 \%$ of search queries occurred in the category "diagnostics" and $46 \%$ in the general category, whereas the national percentages for these categories were $3 \%$ and $68 \%$, respectively. This discrepancy between city and national percentages can also be observed in Kaiserslautern, where $35 \%$ of the searches fell into the category "sarcoidosis forms/organ infestation" and in $41 \%$ into the category "general", whereas the national percentage for the former category was $21 \%$. The categorical distributions in Berlin and Hamburg were similar to the national distribution pattern (Table 3). 


\begin{tabular}{|c|c|c|c|}
\hline Category & Keywords & Absolute search volume & $\begin{array}{l}\text { Search volume per } 100,000 \\
\text { inhabitants }\end{array}$ \\
\hline \multirow{5}{*}{ General } & Sarcoidosis & $1,689,300$ & 2040.5 \\
\hline & Morbus Boeck & 75,000 & 90.6 \\
\hline & Systemic disease & 20,100 & 24.3 \\
\hline & Sarcoidosis nutrition & 19,200 & 23.2 \\
\hline & Sarcoidosis lung life expectancy & 18,730 & 22.6 \\
\hline \multirow{5}{*}{$\begin{array}{l}\text { Form of sarcoidosis/organ manifesta- } \\
\text { tion }\end{array}$} & Löfgren’s syndrome & 99,380 & 120.0 \\
\hline & Sarcoidosis lung & 81,910 & 98.9 \\
\hline & Neurosarcoidosis & 56,740 & 68.5 \\
\hline & Sarcoidosis skin & 41,650 & 50.3 \\
\hline & Lungsarcoidosis & 25,980 & 31.4 \\
\hline \multirow{5}{*}{ Symptoms } & Sarcoidosis symptoms & 35,610 & 43.0 \\
\hline & Pulmonary hyperinflation & 20,150 & 24.3 \\
\hline & Sarcoidosis skin pictures & 9340 & 11.3 \\
\hline & Sarcoidosis skin itching & 7120 & 8.6 \\
\hline & Neurosarcoidosis symptoms & 6500 & 7.9 \\
\hline \multirow{5}{*}{ Therapy } & Sarcoidosis therapy & 23,880 & 28.8 \\
\hline & Sarcoidosis forum & 18,730 & 22.6 \\
\hline & Sarcoidosis specialist & 5600 & 6.8 \\
\hline & Sarcoidosis treatment & 4180 & 5.0 \\
\hline & Sarcoidosis therapy guidelines & 3350 & 4.0 \\
\hline \multirow{5}{*}{ Diagnostics } & Sarcoidosis diagnostics & 16,250 & 19.6 \\
\hline & Sarcoidosis values & 6370 & 7.7 \\
\hline & Sarcoidosis laboratory & 5580 & 6.7 \\
\hline & Ace sarcoidosis & 4690 & 5.7 \\
\hline & Sarcoidosis X-ray & 3580 & 4.3 \\
\hline
\end{tabular}

Table 2. The five most frequently searched keywords related to sarcoidosis per category in the whole of Germany.

Time course of search behavior. The national search volume of Google search queries related to sarcoidosis increased from July 2015 to June 2019 for Germany (Fig. 3). The month with the lowest search volume per 100,000 inhabitants was December 2015 (60 searches/100,000 inhabitants), whereas April 2019 had the highest search volume (138 searches/100,000 inhabitants). Overall, the data indicated a small increase in search volume within the study period. Especially, in European springtime (March-May) people tended to search more often for sarcoidosis, whereas in European winter (December-February) a decrease in search volume was observed.

Furthermore, the 17 cities were further divided based on their geography into groups of northern, southern, eastern, and western cities to get an overview of the monthly range in search behavior, based on geographical differences. In Northern Germany, Kiel had the highest and Bremen the lowest number of search queries (Fig. 4a). In Eastern Germany, the number of search queries in Erfurt was higher than that in Dresden and Berlin (Fig. 4b), with a particularly sharp increase from February to June 2016. A wide range in search volume was observed in cities in Western Germany, where for example the search volume ranged between 222 per 100,000 inhabitants (December 2018) and 522 per 100,000 inhabitants (April 2019) for Kaiserslautern. In Southern Germany, Freiburg had the highest volume during the whole study period, with high values in July 2015 (557 searches/100,000 inhabitants), and April 2019 (570 searches/100,000 inhabitants), which were the highest recorded search volumes among all cities throughout the entire study period. All cities recorded a distinct increase in April 2019 (Fig. 4a-d).

\section{Discussion}

The aim of the study was to identify areas of unmet need and geographical as well as seasonal factors that influence sarcoidosis as the basis for optimizing sarcoidosis care by leveraging Internet search data. The most commonly searched was the word "sarcoidosis", followed by more specific search terms such as "Löfgren's syndrome" and "sarcoidosis lung". Furthermore, even more specific diagnostic terms such as "ACE laboratory value" were searched for. The search volume of these relatively specific keywords might imply that affected individuals search for information online using terms they have heard as part of their own diagnosis or heard from individuals who have received a sarcoidosis diagnosis.

The three most frequently searched terms, "sarcoidosis", "Löfgren's syndrome”, and "sarcoidosis lung", are representative of their respective diagnoses, since sarcoidosis summarizes all sarcoidosis subtypes, Löfgren's syndrome is found in up to $50 \%$ of all cases, and the lung is the most frequently affected organ ${ }^{5}$. This is further emphasized by the fact that two of the five most frequently searched keywords are organ manifestations ("sarcoidosis skin" and "sarcoidosis lung"), which reflect how this multisystemic disease often manifests itself first 


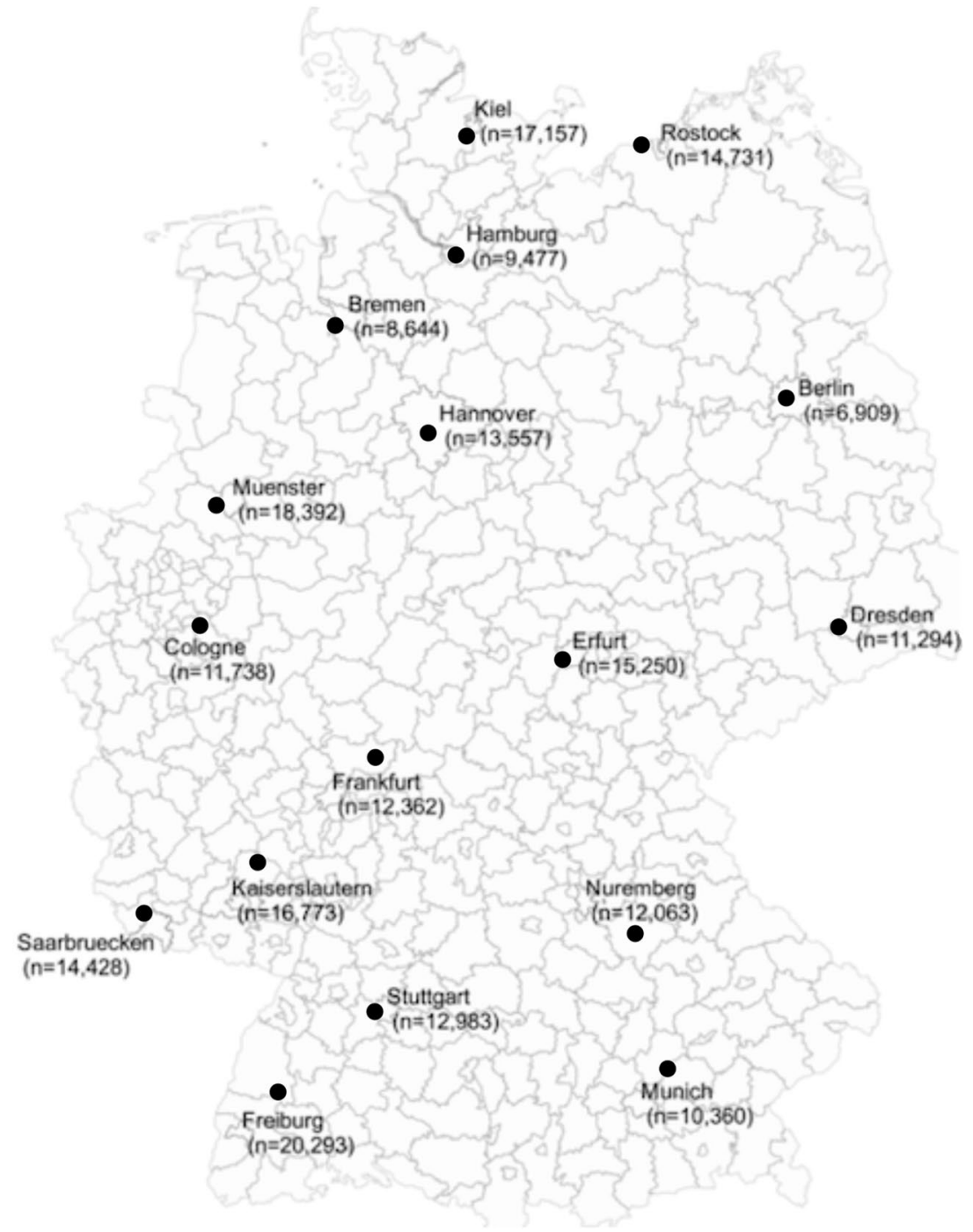

Figure 2. Search volume per 100,000 inhabitants of terms related to sarcoidosis in 17 large German cities between July 2015 and June 2019. QGIS.org, 2021. QGIS Geographic Information System. QGIS Association. http://www.qgis.org.

in the lungs and the skin ${ }^{5,25}$. The high interest in neurosarcoidosis seen with "neurosarcoidosis" being among the top five search terms is notable considering since it is a rare organ manifestation that only occurs in 5-10\% of all cases in conventional studies ${ }^{26}$. This might underline people's fear of this sarcoidosis subtype or just an exaggerated interest due to the rarity of neurosarcoidosis. For example, "eye melanoma" is a rare disease shown to have similarly high interest in the population ${ }^{21}$. Another explanation is an increased interest stemming from individuals who show neurological symptoms but have not been diagnosed with neurosarcoidosis informing themselves online on this rare organ manifestation.

The study results indicate an increase in search volume for sarcoidosis during springtime. One study does indicate differences in terms of decreasing numbers in autumn compared to higher numbers in spring, which however, where not statistical significance ${ }^{13}$. One possible explanation for the observed increase in search volume in this study is the preceding wave of influenza. Granulomas of (symptomless) pulmonary sarcoidosis are often discovered by chance in chest X-rays, which are performed to identify influenza complications ${ }^{27}$. Another possible explanation is the strain on the immune system by high pollen counts in the spring that prompt inflammation of the respiratory epithelium through oxidase and neutrophil activity. This could augment the risk for developing sarcoidosis and exacerbate chronic sarcoidosis symptoms ${ }^{28,29}$. This assumption is supported by the fact that every year the volume of search terms was higher in April and May than in the other months. The deterioration of chronic lung diseases caused by pollen has already been observed in other studies on asthma ${ }^{30,31}$. Climate differences could also play a role, which would explain the decline in searches during the winter months. However as mentioned above, in other studies no statistically significant differences could be found, which makes the results of this websearch analysis even more interesting ${ }^{13}$. Furthermore, April 2019 was particularly striking with search results rising to 138 searches/100,000 inhabitants. That year the Foundation for Sarcoidosis 


\begin{tabular}{|c|c|c|c|c|c|c|c|c|}
\hline & \multirow[b]{2}{*}{$\begin{array}{l}\text { Number of } \\
\text { inhabitants }\end{array}$} & \multirow[b]{2}{*}{ Number of searches } & \multirow[b]{2}{*}{$\begin{array}{l}\text { Number of searches } \\
\text { per } 100,000 \\
\text { inhabitants }\end{array}$} & \multicolumn{5}{|c|}{ Internet searches percentage distribution according to the categories } \\
\hline & & & & Diagnostics (\%) & General (\%) & $\begin{array}{l}\text { Form of sarcoidosis/ } \\
\text { organ manifestation } \\
\text { (\%) }\end{array}$ & Symptoms (\%) & Therapy (\%) \\
\hline Germany & $83,000,000$ & $3,068,200$ & 3706.0 & 3 & 68 & 21 & 4 & 4 \\
\hline Berlin & $3,613,495$ & 249,660 & 6909.1 & 7 & 57 & 24 & 6 & 6 \\
\hline Bremen & 568,006 & 49,100 & 8644 & 8 & 47 & 30 & 7 & 8 \\
\hline Dresden & 551,072 & 62,240 & 11,294 & 8 & 48 & 29 & 7 & 7 \\
\hline Erfurt & 212,988 & 32,480 & 15,250 & 11 & 44 & 30 & 8 & 7 \\
\hline Frankfurt & 746,878 & 92,330 & 12,362 & 9 & 50 & 27 & 7 & 7 \\
\hline Freiburg & 229,636 & 46,600 & 20,293 & 11 & 46 & 30 & 6 & 7 \\
\hline Hamburg & $1,830,584$ & 173,490 & 9477 & 8 & 54 & 25 & 7 & 7 \\
\hline Hannover & 535,061 & 72,540 & 13,557 & 9 & 49 & 28 & 6 & 7 \\
\hline Kaiserslautern & 99,684 & 16,720 & 16,773 & 8 & 41 & 35 & 8 & 8 \\
\hline Kiel & 247,943 & 42,540 & 17,157 & 9 & 47 & 30 & 7 & 7 \\
\hline Cologne & $1,080,394$ & 126,820 & 11,738 & 8 & 52 & 26 & 7 & 7 \\
\hline Munich & $1,456,039$ & 150,840 & 10,360 & 9 & 53 & 25 & 6 & 7 \\
\hline Muenster & 313,559 & 57,670 & 18,329 & 11 & 46 & 30 & 6 & 8 \\
\hline Nuremberg & 515,201 & 62,150 & 12,062 & 9 & 47 & 29 & 8 & 8 \\
\hline Rostock & 208,409 & 30,700 & 14,730 & 9 & 45 & 32 & 7 & 7 \\
\hline Saarbruecken & 180,966 & 26,110 & 14,428 & 10 & 42 & 33 & 8 & 7 \\
\hline Stuttgart & 632,743 & 82,150 & 12,983 & 9 & 49 & 27 & 7 & 7 \\
\hline
\end{tabular}

Table 3. Proportional distribution of the search volume according to categories of sarcoidosis-related keywords in Germany and 17 major German cities between July 2015 and June 2019. Diagnosis, general, form of sarcoidosis/organ manifestation, symptoms, therapy provide the names for the categories attributed to the search terms: "symptoms" (e.g. "sarcoidosis symptoms"), "diagnostics" (e.g. "ace laboratory value"), "form of sarcoidosis/organ infestation" (e.g. "sarcoidosis nerves"), "therapy" (e.g. "alternative method sarcoidosis") and "general" category (e.g. "sarcoidosis", "Boeck’s disease"). Bold similar to Germany-wide distribution, italics diverging distribution pattern compared to Germany-wide categorical distribution.

\section{Germany (all regions)}

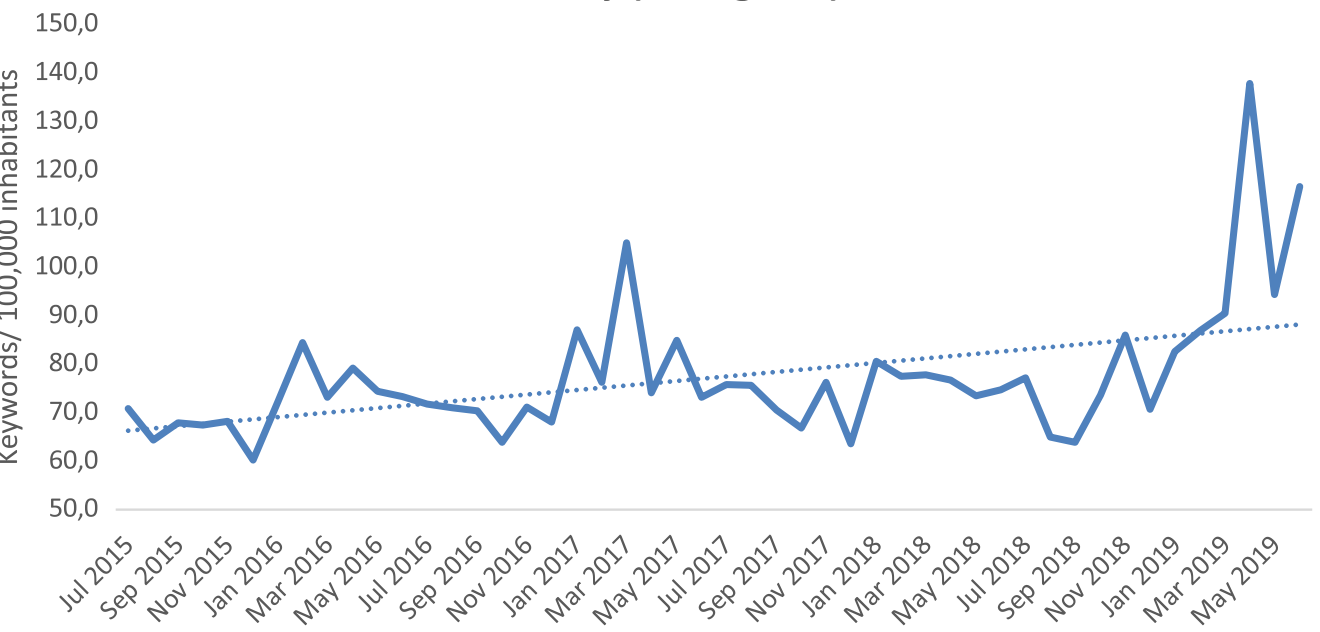

Figure 3. German national wide number of Google search queries related to sarcoidosis from June 2015 to July 2019 per 100,000 inhabitants (424 keywords; $\mathrm{n}=3,068,200, \mathrm{nr}=3706.0$ searches/100,000 inhabants).

Research (FSR) declared April "Sarcoidosis Month" and through campaigns sought to increase awareness about the disease, which would possibly explain this substantial peak in search volume.

Keyword distribution in different German cities. The result showed that the search volume per 100,000 inhabitants was sustainable higher in smaller cities such as Freiburg and Muenster than in larger cities like Berlin and Hamburg. The lower number of search queries in bigger cities might be explained by the better access to medical care with specialists in larger cities than in smaller cities. There are some studies on the 

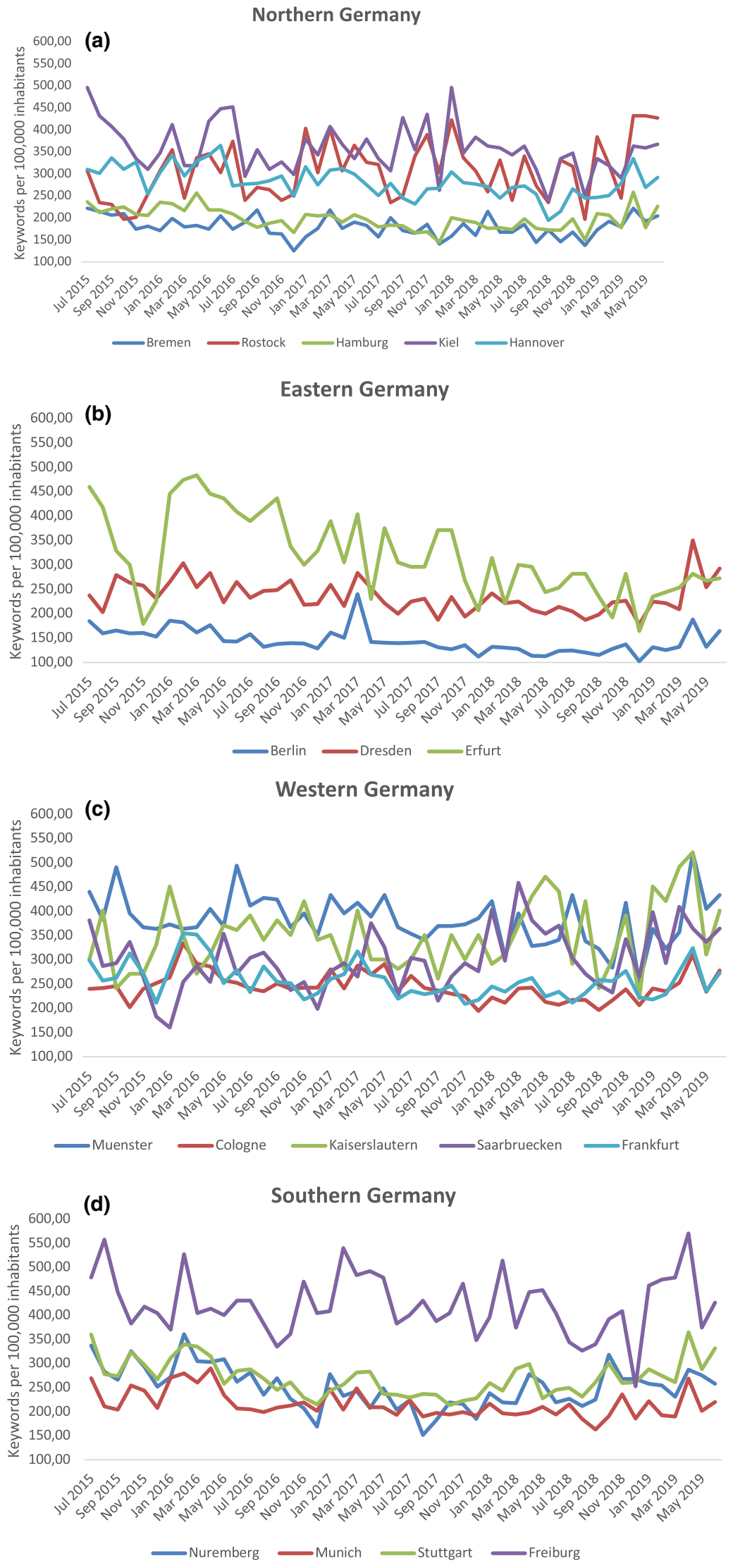

Figure 4. (a) Number of Google search queries on sarcoidosis in Northern Germany from June 2015 to July 2019 per 100,000 inhabitants. (b) Number of Google search queries on sarcoidosis in Eastern Germany from June 2015 to July 2019 per 100,000 inhabitants. (c) Number of Google search queries on sarcoidosis in Western Germany from June 2015 to July 2019 per 100,000 inhabitants. (d) Number of Google search queries on sarcoidosis in Southern Germany from June 2015 to July 2019 per 100,000 inhabitants. 
over- and undersupply of specialists in rural areas, such as neurologists and psychiatrists, but none specifically related to sarcoidosis ${ }^{32,33}$. However, it can be assumed that there are differences in access to specialists between urban and rural regions because of disparities in infrastructure and the allocation of health insurance fund seats according to the density of the patient population ${ }^{34}$. Previous studies have shown that people living in rural areas are less likely to visit specialists ${ }^{35}$. Accordingly, people living closer to specialists might consult a specialist instead of using Google for health-related information. In the case of sarcoidosis, this could mean that people living in rural areas are less likely to be diagnosed ${ }^{19,36}$. In smaller cities people might get the diagnosis, but as the medical care to specialists is less in comparison to big cities, they have less opportunity to ask questions about the disease. This deficit in information supply might be compensated by search queries. Another explanation could be that smaller cities like Freiburg, Muenster, Kiel, and Rostock, have a higher proportion of medical students and healthcare professionals within the respective inhabitants than large cities do and that the higher search volume of sarcoidosis related keywords in these cities can be attributed to medical students performing online research on the disease. Overall, the search queries in each city were higher than the national average. This was particularly noticeable in Kiel, Freiburg, and Erfurt. This phenomenon could also be explained by the lack of diagnosis in rural areas. The high search volume in Freiburg may be explained by the presence of the National Action Alliance for People with Rare Diseases, which has established appropriate structures for patient care in the University Hospitals of Freiburg and Tübingen ${ }^{37}$. Furthermore, it was shown that older people use the Internet less common, which might be one reason for the lower number of search queries in the whole of Germany compared to the cities examined ${ }^{38}$. Assuming that a higher search volume correlates with a higher prevalence of sarcoidosis like shown in studies on melanoma ${ }^{36}$, the study results contradict those from a previous study that found a higher prevalence among people living in rural areas ${ }^{12}$. The results of the Google analysis could accordingly indicate a much higher prevalence of sarcoidosis than previously assumed.

Ultimately, the discrepancy in search volume between individual cities and Germany as a whole can suggest an actual variation in sarcoidosis prevalence, but it also reflects different demographic distributions and better availability of resources, closer networking such as self-help groups and medical care in urban areas.

Limitations. There are some study limitations. Google analyses are limited to people who have access to the Internet and use Google as a search engine. Although 95 percent of Germans use Google as a search engine, only including data collected from Google excludes information from a portion of the population. In general, young people use the Internet more than older people. On user demographics, the study is not able to show correlations with people's age, gender, or nationality. Accordingly, the study might underestimate the disease burden through exclusion of elderly members of the population as well as foreign, non-German speaking residents. Another limitation of the present study is that the searches do not necessarily have to originate from affected individuals, but also from physicians, medical students, or relatives who are interested in the topic as well. It must be taken into consideration that most of the cities included in the study have large medical schools, which can lead to a disproportionately high number of searches through online student activity and medical research. Accordingly, this could be another explanation for the higher number of searches per 100,000 inhabitants in Freiburg for example. Furthermore, there is no information whether a few individuals searched very often or whether many people searched once or twice. So far, there is no study that assessed the correlation between online searches and the prevalence of sarcoidosis. However, considering other studies, a correlation between the number of Google searches and the number of registered cases such as skin cancer or multiple sclerosis was found ${ }^{36,39}$. Another study reported that online tools play an important role in gathering information regarding rare diseases ${ }^{40}$. Based on these findings, it can be assumed that there is a relation between search behavior and the occurrence of sarcoidosis. Another limitation is that Google through its autocomplete function provides search suggestions that could as well distort search behavior. Moreover, data provided by Google Ads Keyword Planner are based on monthly estimations instead of exact numbers and thus might slightly differ from the actual search volume. Therefore, the search behavior in cities might be rather overestimated, while it might be underestimated for Germany as a whole ${ }^{19,36}$.

\section{Conclusion}

The study demonstrated that there is an unmet need for information within affected individuals and the population for sarcoidosis-related keywords, as the search volume for this rare disease is relatively high in relation to the estimated prevalence in Germany. Another perspective of course could be that the prevalence is higher than previously assumed based on conventional studies, given the high number of searches in the cities in comparison to the overall search volume across the whole of Germany. Furthermore, low web search numbers in rural areas indicate a diagnostic gap and the clearly increased web search frequency in spring suggests environmental and climatic trigger factors, worthy of further investigation.

\section{Data availability}

All data generated or analysed during this study are included in this published article.

Received: 26 February 2021; Accepted: 30 September 2021

Published online: 21 October 2021

\section{References}

1. Costabel, U. \& Hunninghake, G. ATS/ERS/WASOG statement on sarcoidosis. Sarcoidosis statement committee. American thoracic society. European respiratory society. World association for sarcoidosis and other granulomatous disorders. Eur. Respir. J. 14, 735-737 (1999). 
2. Gerke, A. K., Judson, M. A., Cozier, Y. C., Culver, D. A. \& Koth, L. L. Disease burden and variability in sarcoidosis. Ann. Am. Thorac. Soc. 14, 421-428 (2017).

3. Kreuter, M., Prasse, A. \& Costabel, U. Seltene Lungenerkrankungen (ed. Kreuter, M.) 170-187 (Springer, 2016).

4. Spagnolo, P. et al. Pulmonary sarcoidosis. Lancet Respir. Med. 6(5), 389-402 (2018).

5. Grunewald, J. et al. Sarcoidosis (Primer). Nat. Rev. Dis. Primers. 5, 49 (2019).

6. Judson, M. A. et al. The diagnostic pathway to sarcoidosis. Chest 123, 406-412 (2013).

7. Pietinalho, A. et al. The frequency of sarcoidosis in Finland and Hokkaido, Japan. A comparative epidemiological study. Sarcoidosis 12, 61-67 (1995)

8. Deubelbeiss, U., Gemperli, A., Schindler, C., Baty, F. \& Brutsche, M. H. Prevalence of sarcoidosis in Switzerland is associated with environmental factors. Eur. Respir. J. 35, 1088-1097 (2010).

9. Pabst, S., Skowasch, D. \& Grohé, C. Sarkoidose. Pneumologie 66, 96-110 (2012).

10. Rossides, M. et al. Are infectious diseases risk factors for sarcoidosis or a result of reverse causation? Findings from a populationbased nested case-control study. Eur. J. Epidemiol. 35, 1087-1097 (2020).

11. Newman, L. S. et al. A case control etiologic study of sarcoidosis: Environmental and occupational risk factors. Am. J. Respir. Crit. Care Med. 170, 1324-1330 (2004).

12. Arkema, E. V., Grunewald, J., Kulberg, S., Eklund, A. \& Askling, J. Sarcoidosis incidence and prevalence: A nationwide registerbased assessment in Sweden. Eur. Respir. J. 48, 1690-1699 (2016).

13. Ungprasert, P., Crowson, C. S. \& Matteson, E. L. Seasonal variation in incidence of sarcoidosis: A population-based study, 19762013. Thorax 71, 1164-1166 (2016).

14. Beghè, D. et al. Sarcoidosis in an Italian province. Prevalence and environmental risk factors. PLoS One 12, 0176859. https://doi. org/10.1371/journal.pone.0176859 (2017).

15. Baughman, R. P. et al. Sarcoidosis in America. Analysis based on health care use. Ann. Am. Thorac. Soc. 13, 1244-1252 (2016).

16. Nicholson, T. et al. Sarcoidosis in Ireland: Regional differences in prevalence and mortality from 1996-2005. Sarcoidosis Vasc. Diffuse Lung Dis. 27, 111-120 (2010).

17. Amante, D. J., Hogan, T. P., Pagoto, S. L., English, T. M. \& Lapane, K. L. Access to care and use of the Internet to search for health information: Results from the US National Health Interview Survey. J. Med. Internet Res. 17, 106. https://doi.org/10.2196/jmir. 4126 (2015).

18. Beck, F. et al. Use of the internet as a health information resource among French young adults: Results from a nationally representative survey. J. Med. Internet Res. 16, 128. https://doi.org/10.2196/jmir.2934 (2014).

19. Tizek, L. et al. Influence of climate on google internet searches for pruritus across 16 German cities: Retrospective analysis. J. Med. Internet Res. 21, e13739. https://doi.org/10.2196/13739 (2019).

20. Ginsberg, J. et al. Detecting influenza epidemics using search engine query data. Nature 457, 1012-1014 (2009).

21. Seidl, S., Schuster, B., Rüth, M., Biedermann, T. \& Zink, A. What do Germans want to know about skin cancer? A nationwide google search analysis from 2013 to 2017. J. Med. Internet Res. 20, 10327. https://doi.org/10.2196/10327 (2018).

22. Scheerer, C. et al. Googling for ticks and borreliosis in Germany: Nationwide google search analysis from 2015 to 2018. J. Med. Internet Res. 22, 18581. https://doi.org/10.2196/18581 (2020).

23. Zink, A. et al. Medical needs and major complaints related to pruritus in Germany: A 4-year retrospective analysis using Google AdWords Keyword Planner. J. Eur. Acad. Dermatol. Venereol. 33, 151-156 (2019).

24. Geodesy., F.A.F.C.A. QGIS version 2.14.22. http://www.geodatenzentrum.de/geodaten/gdz_rahmen.gdz_div?gdz_spr=deu\&gdz_ akt_zeile $=5 \& g d z \_a n z \_z e i l e=1 \& g d z \_u n t \_z e i l e=0 \& g d z \_u s e r \_i d=0$. Accessed 03 Feb $2020(2016)$.

25. Baughman, R. P. et al. Clinical characteristics of patients in a case control study of sarcoidosis. Am. J. Respir. Crit. Care Med. 164, 1885-1889 (2001)

26. Culver, D. A., Neto Ribeiro, M. L., Moss, B. P. \& Willis, M. A. Neurosarcoidosis. Semin. Respir. Crit. Care Med. 38, 499-513. https:// doi.org/10.1055/s-0037-1604165 (2017).

27. Loddenkemper, R., Kloppenborg, A., Schoenfeld, N., Grosser, H. \& Costabel, U. Clinical findings in 715 patients with newly detected pulmonary sarcoidosis-Results of a cooperative study in former West Germany and Switzerland. WATL Study Group. Wissenschaftliche Arbeitsgemeinschaft fur die Therapie von Lungenkrankheitan. Sarcoidosis Vasc. Diffuse Lung Dis. 15, 178-182 (1998).

28. Boldogh, I. et al. ROS generated by pollen NADPH oxidase provide a signal that augments antigen-induced allergic airway inflammation. J. Clin. Investig. 115, 2169-2179 (2005).

29. Gilles, S. et al. Pollen allergens do not come alone: Pollen associated lipid mediators (PALMS) shift the human immue systems towards a T H 2-dominated response. Allergy Asthma Clin. Immunol. 5, 3. https://doi.org/10.1186/1710-1492-5-3 (2009).

30. Gilmour, M. I., Jaakkola, M. S., London, S. J., Nel, A. E. \& Rogers, C. A. How exposure to environmental tobacco smoke, outdoor air pollutants, and increased pollen burdens influences the incidence of asthma. Environ. Health Perspect. 114, 627-633 (2006).

31. Boulet, L. P. et al. Asthma and increases in nonallergic bronchial responsiveness from seasonal pollen exposure. J. Allergy Clin. Immunol. 71, 399-406 (1983).

32. Koller, D. et al. Ambulatory health services utilization in patients with dementia-Is there an urban-rural difference?. Int. J. Health Geogr. 9, 59. https://doi.org/10.1186/1476-072X-9-59 (2010).

33. Comer, J. \& Mueller, K. Access to health care: Urban-rural comparisons from a midwestern agricultural state. J. Rural Health. 11, $128-136$ (1995).

34. Kopetsch, T., Bedarfsplanung: Geregelt wird nur die Verteilung. Deutsches Ärzteblatt online, Preprinted at: https://www.aerzt eblatt.de/archiv/46645/Bedarfsplanung-Geregelt-wird-nur-die-Verteilung. Accessed 10 Oct 2020 (2005).

35. Tizek, L. et al. Regional differences in medical needs and care for skin cancer across Bavaria: Confronting the gap. Eur. J. Dermatol. 30, $119-126(2020)$.

36. Tizek, L. et al. Interest in skin cancer in urban populations: A retrospective analysis of google search terms in nine large German cities. Acta Derm Venereol. 99, 797-804 (2019).

37. Müller-Quernheim, J. Sarcoidosis and ild around the world-Germany. Preprinted at: https://www.wasog.org/sarcoidosis-andild-around-th-world.html\#Germany. Accessed 10 Oct 2020 (2020).

38. Henger, R. Alterung der Gesellschaft im Stadt- Land Vergleich 2019. Preprinted at: https://www.iwkoeln.de/studien/iw-kurzberich te/beitrag/ralph-henger-christian-oberst-alterung-der-gesellschaft-im-stadt-land-vergleich-420704.html. Accessed 10 Oct 2020 (2019).

39. Moccia, M. et al. Google Trends: New evidence for seasonality of multiple sclerosis. J. Neurol. Neurosurg. Psychiatry. 87, 1028-1029 (2016).

40. Morgan, T. et al. Using the internet to seek information about genetic and rare diseases: A case study comparing data from 2006 and 2011. JMIR Res. Protoc. 3, 10. https://doi.org/10.2196/resprot.2916 (2014).

\section{Author contributions}

C.H., L.T., M.R., M.S., T.B. and A.Z. conceived and planned the experiments. C.H., L.T. and A.Z. planned and carried out the data generation and statistical analysis. C.H., L.T., M.R., M.S., T.B. and A.Z. contributed to the 
interpretation of the results. C.H. and A.Z. took the lead in writing the manuscript. All authors provided critical feedback and helped shape the research, analysis and manuscript.

\section{Funding}

Open Access funding enabled and organized by Projekt DEAL. Funded by the Technical University of Munich and Karolinska Institutet.

\section{Competing interests}

The authors declare no competing interests.

\section{Additional information}

Correspondence and requests for materials should be addressed to A.Z.

Reprints and permissions information is available at www.nature.com/reprints.

Publisher's note Springer Nature remains neutral with regard to jurisdictional claims in published maps and institutional affiliations.

(c) (i) Open Access This article is licensed under a Creative Commons Attribution 4.0 International License, which permits use, sharing, adaptation, distribution and reproduction in any medium or format, as long as you give appropriate credit to the original author(s) and the source, provide a link to the Creative Commons licence, and indicate if changes were made. The images or other third party material in this article are included in the article's Creative Commons licence, unless indicated otherwise in a credit line to the material. If material is not included in the article's Creative Commons licence and your intended use is not permitted by statutory regulation or exceeds the permitted use, you will need to obtain permission directly from the copyright holder. To view a copy of this licence, visit http://creativecommons.org/licenses/by/4.0/.

(C) The Author(s) 2021 